\title{
Comparitive Study Between Cnventional and Hyperfractionaltion Radiation Therapy for The Treatment of Brain Stem Tumors
}

\author{
Dr. Laila Fares* (MD), Mamdouh Salama** (MD) Manal Moawad*(MD) \\ Sohair Helmy (MD)* and Dr. Hany M. Abd El-Aziz*
}

* Radiation Oncology and ** Neurosurgery Departments of Ain Shams University.

\begin{abstract}
:
Brain stem tumors are special challenge because primarily of their location and the neurologic effect caused by these groups of tumors (Paul 1997).

Radiation therapy improves survival for brain stem tumors and stabilizes or reverses neurologic dysfunction in $75-90 \%$ of patients.

The main domain of applicability of hyperfractionation would be in tumor sites where the dose limiting tissue is late reacting and whose effective control requires the delivery of doses beyond tolerance (Awwad, 1990), hence the rationale for the use of hyperfractionation in brain stem lesions.

The purpose of this work is to find out the best radiation protocol in this group of patients comparing conventional fractionation and hyperafractionation.

This study included 46 patients which brainstem tumors treated in Radiation Oncology and Neurosurgery Departments Ain Shams University between February 1998 and May 2000.

These patients had been randomly distributed in 2 groups A and B. The first group treated by conventional radiotherapy protocol and the second group treated by hyperfractionation radiation protocol.

By the end of the study, the median over all survival and median time for disease progression were calculated for each group.

Age, neurologic status at presentation and anatomical location were significant prognostic factors.

By the end of this study clicinal evalualion had no significant difference between both groups but the median over all survival for the two groups was 10.5 months, the median survival for group A was 9.4 months and that for group B was 11.5 months which was statistically significant $\mathrm{P}<0.02$.

On the other hand the percentage of patient with one year survival for group A \& B $(22 \%, 32 \%)$ respectively.

The rate of acute (early) reaction of radiation is slightly higher in hyperfracticmaticm than conventional fractionation but the late reactions occur with same frequency with both regimens.
\end{abstract}

Refree : Prof ; Hamdy Zawam 
Performance status: all patients should have karnofsky scale of performance states $70 \%$ or more at the beginning of

\section{Introduction:}

treatment.

Over the last 30 years, radiation therapy for neoplasm of the C.N.S. has attained a respected role, providing the opportunity for prolonged survival, regression of neurological deficits and improving the quality of life (American Cancer Society 1996).

Brain stem lesions are much more common in children than adults accou nting for $20 \%$ of neuroepithelial tumors in children compared wich only $2 \%$ in adults (Cortan et al., 1994).

In the brainstem region, astrocy tomas are the commonest type (20\%) followed by glioblastoma and ependy moma (Tatter et al., 1996).

Biopsy of brain stem tumors for confirmation of the disagnosis and for definite tumor grading using streotactic technique guided by CT and MRI have a very low rate of complication while attempts for complete resection is usually contraindicated (Coffey et al., 1990).

\section{Patients \& Methods}

This study included 46 patients with brain stem tumors, who were randomly distributed in two treatment groups. A and B. This study was carried out in Neurosurgical and Radiation Oncology Departments, Ain Shams University between February 98 and January 2001.

Group "A" included 24 patients treated by conventional radiotherapy protocol. Group "B" included 22 patients treated by hyperfractionation radiation protocol.

\section{Eligibility Criteria:}

Age: all patients should be more than 4 years old.

Histologically proven pathology by steriotactic biopsy.

Adequate organ function.

\section{Treatment Protocol:}

All patients were treated with megavoltage photon beam with energies ranging from 4 to $6 \mathrm{Mv}$.

Parallel opposed lateral portals were used with the target volume including the tumor and $2 \mathrm{~cm}$ margin of normal brain parenchyma.

Group A: Received conventional radiotherapy treatment $1.8 \mathrm{~Gy} /$ fraction, once daily for 5 fractions for a total dose of 54-60 Gy over a period of 6-7 weeks.

Group B: Received hyperfractionation radiotherapy regimen. 1-1.2 Gy/frac tion, twice daily, 5 days a week with interfractional interval of 6 hours. The total dose was 60-72 Gy with the over all time 5.5-7 weeks.

Evaluation of response, relapse toxicity and outcome.

All patients should have radiographic studies (C.T. or MRI) performed 6-8 weeks after completion of irradiation and compared with the pretreatment neuroradiographic studies for evidence of changing character in the lesion (necrosis, Hemorrhage, cystic change).

\section{Statistical Methods:}

The progression free survival and over all survival (from the time of diagnosis) were measured.

Chi-square method was used to compare between the 2 groups. Also response rates, toxicities and prognostic criteria were evaluated.

\section{Results}




\section{Dr. Laila Fares et al}

The total number of patients was 46 (24 in group A, 22 in group B), with median age 18,19 years for both groups respectively. Male to female ratios was $1: 1.2$ in each group.

Of the 46 patients with brain stem tumors, 32 had pontine inolvement, 3 patients had pure mid brain tumors and 11 had brain stem involvement.

\section{Histopathological Findings.}

The commonest histopathological type was anaplastic astrocytoma followed

by glioblastoma multiform. (48\%, 39\%)

respectively the least Common was ependymoma (4\%).

Clinical improvement was reported for $33 / 46(72 \%)$ of patients meanwhile clinical deterioration was evident in $28 \%$ of the patients.

Radiologic follow up 8 weeks after completion of radiotherapy revealed partial response in $30.4 \%$ of patients, stable desease in $41.3 \%$ and progressive disease in $28.3 \%$.

By the end of the study, all patient except. 5 developed subsequent progre ssive disease (89\%) with the median time of disease progression 8 months ( 7 months for group A and 8.5 months for group B.

With the exception of 2 patients, all recurrences were local at the primary tumor site. Those 2 patients had spinal recurrence as proved by MRI and were subjected to spinal irradiation.

The median over all survival for the 2 groups was 10.5 months. The median survival for group A was (9.4) and for group B was (11.5) wich was statistically significant $(\mathrm{P}<0.02)$.

One year Survival for group A \&B were ( 22\% , 32\%) respectively .

\section{Prognostie factors:}

Age, neurological status, location of the tumor and pathology of tumor wre correlated to the survival.

In this study, patients above 18 years of age had better over all survival $(\mathrm{P}=$
0.02), meanwhile patients with poor neurological conditions at presentation had poor prognosis using both relapse free survival and over all survival as endpoints $(\mathrm{P}=0.03)$.

Univariant analysis of the relapse free survival of patients revealed better progrnosis for patients with mid brain than those tumors invovlving pons and medulla with median relapse free survival of 41 weeks and 29 weeks respectively with a difference stastist ically significant $(\mathrm{P}<0.01)$.

\section{Discussion}

The primary objective data of this study was to evaluate the hyper fractionation therapy protocol in this particular group of tumors with poor prognosis even after conventional radiotherapy treatment and to compare the difference in the efficacy and toxicity between the two regimens (comventional and hyperfractionation)

The total number of patients was 46 (25 male and 21 females ) in two treatment groups $\mathrm{A}$ and $\mathrm{B}$.

The over all clinical evaluation showed $78 \%$ clinical improvement (33/46), and clinical deterioration in $27 \%(13 / 46)$ Eifel et al. (1990) had reported $75.90 \%$ clinical improvement and stabilization of reurelogic dysfunction.

As regard the radiologic evaluation, the partial response was reported in $30 \%$ of both groups but the response rates were higher for group B (33\%) compared to group A $(27 \%)$ these results were nearly similar to that reported by Pardos et al. (1995) who reported partial response of $30.8 \%$ in hyperfractionation therapy.

The difference in the over all survival between group A and B was statistically significant $(P=0.02)$ indicating better survival results of hyperfractionation compared to 10.5 months median 
survival reported by Freeman and his colleagues in 1993.

Both liu et al., (1999) and Schild et al., 1998 reported that median over all survival were 17.1 month and 19 months respectively of their patients who had received hyperfractionation after surgery.

This study was designed to evaluate prognostic factors. Age was a significant prognostic factors and patients above 18 years of age had better survival than younger patients $(\mathrm{P}$. $=0.02$ )

This finding was reported also by Landolfi et al., 1998 and Selvapandian et al., 1999 who reported shorter survival in pediatric age group.

The neurologic condition at presentation was a significant prognostic factor (P 0.0-3) similar to that mentioned by Liu et al., 1999, indicating that cranial neuropathy and long tract sign is a prognostic factor $(\mathrm{P}$ $=0.036$ )

Univariant analysis of the patients with brain stem tumors revealed better relapse free survival for patients with tumors affecting the midbrain and thalamic region compared to those involving pons and medulla and the difference was statistically significant $\mathrm{P}$ $<0.01$. Similar results in the study done by Schild et al., 1998. In a recent study carried out by Fisher et al., (2000). The auther concluded that patients with symptoms duration less than 6 months had poor prognosis. Pontine location was associated with worse prgnosis than other brain stem sites $(\mathrm{P}=0.002)$.

Multivariant analysis revealed no association between pathological types and the tumor outcome.

The study showed that hyperfrac tionation radiotherapy is well tolerated regimen of treatment with better results than conventional radiotherapy protocol in the brain stem tumors as regard time to disease progression and over all survival. The rate of acute reaction of radiation is slightly higher than that occurs with conventional fractionation but the late reactions occur with the same frequency in both regimens.

Table (1): Clinical charactristics of 46 patients with Brain stem tumors.

\begin{tabular}{|l|l|l|}
\hline & Group A & Group B \\
\hline No. of patients & 24 & 22 \\
\hline Age in years & & \\
Range & $4-43$ & $5-39$ \\
Median & 18 & 19 \\
\hline Sex & & \\
Male & 13 & 12 \\
Female & 11 & 10 \\
\hline Duration of symptoms and & & \\
Signs (in weeks ) median & 7 & 6.3 \\
\hline
\end{tabular}

Table (2) Site of tumors in 46 patients with brain stem tumors.

\begin{tabular}{|l|l|l|}
\hline Site & No. & $\%$ \\
\hline Pons & $4 / 46$ & 9 \\
Pons \& mid brain & $20 / 46$ & 43 \\
Pons \& cerebellulun & $8 / 46$ & 17 \\
\hline
\end{tabular}




\section{Dr. Laila Fares et al}

\begin{tabular}{|l|l|l|}
\hline Pure mid brain & $3 / 46$ & 7 \\
Entire brain stem & $11 / 46$ & 24 \\
\hline
\end{tabular}

Table (3): Histopathologic subtypes of Brain stem tumors in 46 patients.

\begin{tabular}{|l|l|l|}
\hline Types of pathology & No. & $\%$ \\
\hline Low grade astrocytoma & 4 & 9 \\
\hline Anaplastic astrocytoma & 22 & 48 \\
\hline Glioblastoma multiform & 18 & 39 \\
\hline Ependymoma & 2 & 4 \\
\hline
\end{tabular}

Table (4) Response of treatment in 46 patients with Brain stem tumors.

\begin{tabular}{|l|l|l|l|l|l|}
\hline \multirow{2}{*}{} & \multicolumn{2}{|l|}{ Group A (22) } & \multicolumn{2}{l|}{ Group B (24) } & $\%$ \\
\cline { 2 - 6 } & No. & $\%$ & No & $\%$ & Total \\
\hline Clinical improvement & 16 & $72 \%$ & 17 & $71 \%$ & 72 \\
\hline Clinical deterioration & 6 & $28 \%$ & 7 & $29 \%$ & 28 \\
\hline
\end{tabular}

Table (5) Radiologic evaluation of response in 46 patients

\begin{tabular}{|l|l|l|l|l|l|l|}
\hline & Gr. A22 & \multicolumn{2}{l|}{ Gr. B24 } & Total & \multirow{2}{*}{$\%$} \\
\cline { 2 - 6 } & No. & $\%$ & No. & $\%$ & & \\
\hline Partial response & 6 & $27 \%$ & 8 & $33 \%$ & 14 & $30 \%$ \\
\hline Stable disease & 10 & $46 \%$ & 9 & $37 \%$ & 19 & $41 \%$ \\
\hline $\begin{array}{l}\text { Progressive } \\
\text { disease }\end{array}$ & 6 & $27 \%$ & 7 & $30 \%$ & 13 & $29 \%$ \\
\hline
\end{tabular}

Table (6) Toxicity of the treatment of 46 patients with brainstem tumors.

\begin{tabular}{|l|l|l|l|}
\hline Toxicity & G.A & G.B & Total \\
\hline Skin reaction & 4 & 9 & $13 / 46$ \\
Otitis media & - & 1 & $1 / 46$ \\
Somnolence & 4 & 5 & $9 / 46$ \\
Hearing defect & 1 & 1 & $2 / 46$ \\
Necrotic changes CT and / or MRI & 2 & 3 & $5 / 46$ \\
Behaviour defect. & 1 & 1 & $2 / 46$ \\
White matter changes & 2 & 1 & $3 / 46$ \\
Alopecia at the site of radiation & 24 & 22 & $46 / 46$ \\
\hline
\end{tabular}

Table (7): Median Survival for 46 patients with Brain stem tumors

\begin{tabular}{|l|l|l|l|}
\hline & Group A & Group B & P. value \\
\hline $\begin{array}{l}\text { Median over all } \\
\text { survival (M) }\end{array}$ & 9.4 & 11.5 & 0.02 \\
\hline
\end{tabular}




\begin{tabular}{|l|l|l|l|}
\hline 1y survival & $22 \%$ & $32 \%$ & $>0.05$ \\
\hline
\end{tabular}

\section{Reference}

1. American Cancer Society (1996): Cancer facts and figures. Atlanta, G.A. American Cancer Society.

2. Awwad H.K. (1990): Hyperfractio -nation. In: Radiation Oncology: Radiobiological and physiological presepectives. Kluwer Academic Publishers, 4: 559-568.

3. Coffey R.J. and Lunsford L.D. (1989): Stereotactic surgery for mass lesions of the midbrain and pons. Neurosurgery, 17: 12.

4. Cortan R.S., Kumar V. and Robbins S.L. (1994): Tumours of the central nervous system. In: Cortan R.S., Kumar V. and Robbins S.L. (eds): Robbins Pathologic Basis of Disease, $5^{\text {th }}$ edition. Philadelphia, W.B. Saunders Co., pp. 1342-1356.

5. Fisher P.G., Breiter S.N. and Carson B.S. (2000): A clinicopathological reapprasial of brain stem tumour classififcations. Cancer; 1; 89 (7): 1569-76.

6. Freeman C.R., Bourgowin P.M. and Sanford R.A. (1998): Long term survivors of childhood brainstem gliomas treated with hyperfractionation radiotherapy. The pediatric Oncology Group. Cancer, 1: 77 (3): 555-62.

7. Landolfi J.C., Thaler H.T. and DeAnglis L.M. (1998): Adult brainstem gliomas, Neurology, 51 (4): 1136-9.

8. Liu M., Shean C.Y. and Wong T.T. (1999): Prognostic factors and therapeutic options of pediatric brainstem gliomas. Jpn. J. Clin. Oncol., 28 (8): 474-9.

9. Paul A. Young and Paul H. Young (1997): Basic clinical neuroanatomy, 23-49. Editor: Williams \& Wilkins, International edition.

10. Prados M., Wara W.M., Edwards M.S.B. et al., (1998): Treatment of brain stem and thalamic gliomas with 78 Gy of hyprfractionated radiotherapy. Int. J. Radiat. Oncol. Biol. Phys., 32: 8591.

11. Schild S.E., Stafford S.L. and Brown P.D. (1998): Results of radiotherapy in rainstem tumours. $\mathrm{J}$. Neurooncol., 40 (2) 171-7.

12. Selvapandion S., Rajshekhar V. and Chandy M.J. (1999): Brainstem glioma, outcome in children and adults. Acta Neurosurg., (Wein); 141 (7): 721-6.

13. Tatter S.B., Griffith H. and Charles W. (1996): neuroepithelial tumour of the adult brain. In: Youmans J.R. (ed): Neurological Surgery, $4^{\text {th }}$ edition, Volume 5. W.B. Saunders Company, Philadelphia, London, Toronto, Montreal, PP. 2612-2685.

14. Pardos MD, Wara WM, Fdwards MS et al., (1995): The treatment of brain stem and thalamic gliomawith 67 Gy of hyperfractionated radiation therapy. Int. J. Radiat. Oncol. Biol. Phys. 32: 85-91. 


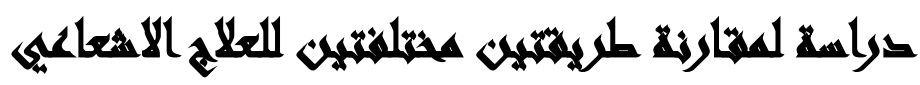

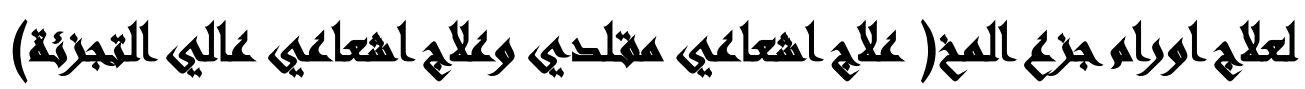

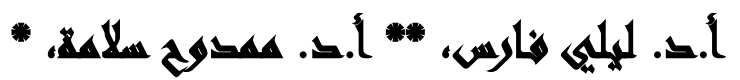

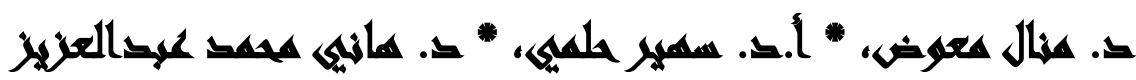

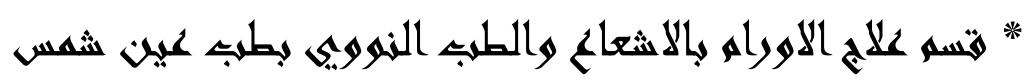

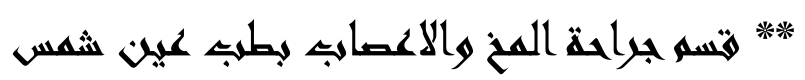

$$
\begin{aligned}
& \text { ملخص البحث }
\end{aligned}
$$

تعتبر اورام جزع الهـخ أحد أهم مجـالات الحث وذلك بسبب مكان الورم وكذا التأثير العصبي الناتج من وجود هذه الأور ام.

ولقد ادي استخدام العلاج الاشعاعي الي تحسن نسبة الثفاء وكذا التقليل من نسبة العجز

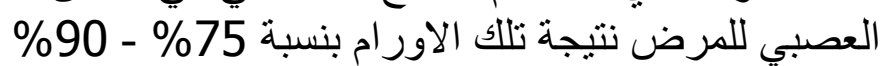

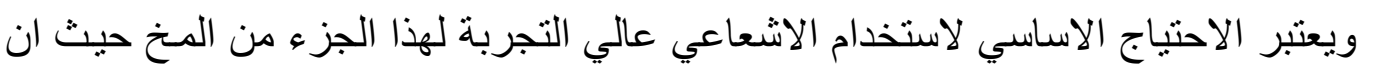

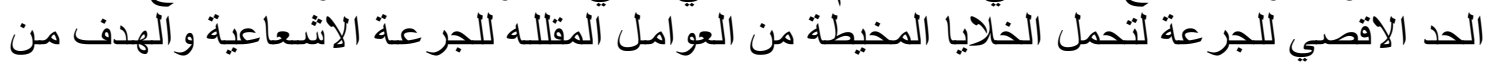

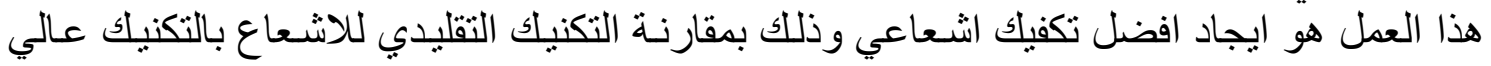

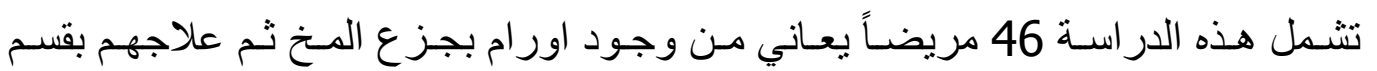

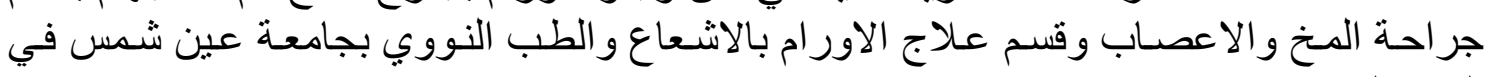
الفترة التي تمتد بين فبر اير 1998 ومايو 2000.

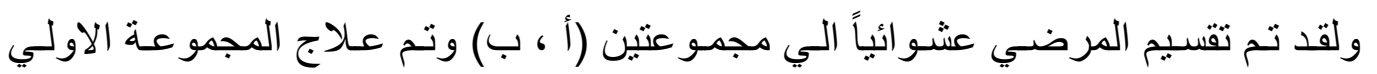

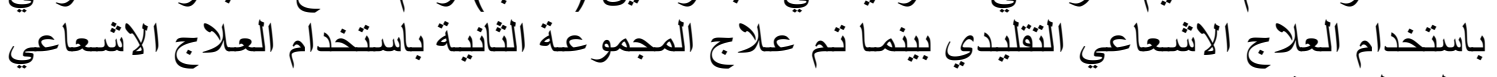

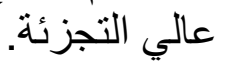

ولقد تم عمل در اسة احصائية من حيث متوسطة الاستمر ار في الحياة وكذا متوسط الفترة

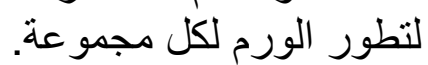

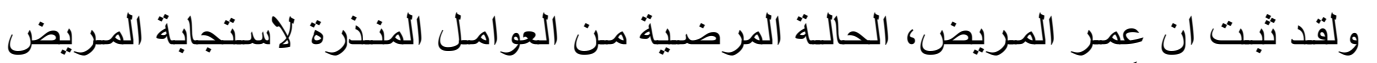

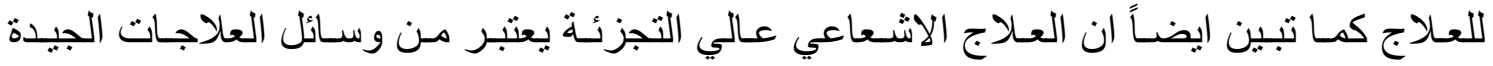

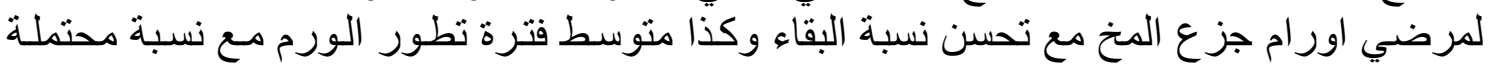

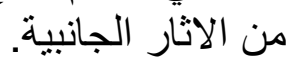

